\title{
Prof. Wolfgang Gernet has handed over the baton to Prof. Daniel Edelhoff
}

\author{
Gottfried Schmalz
}

Received: 2 January 2015 / Accepted: 28 January 2015 / Published online: 7 February 2015

(C) Springer-Verlag Berlin Heidelberg 2015

Since the very beginning of this journal in 1997, Prof. Dr. Wolfgang Gernet has served as an Associate Editor for this journal. Thus, he was one of our founding editors. On Oct 1st 2014, he retired from his position as the chairman of the Department of Prosthetic Dentistry at the Ludwig-Maximilians University Munich, and thus, he asked to step down as Associate Editor for this journal. His plans were to now-after retirement - concentrate more on private matters. Although we all highly appreciated very much his cooperation over so many years, we had to accept this decision. However, I would like to take the opportunity to express my sincere and very special thanks to Prof. Gernet. Since 1997, he processed and evaluated a large number of manuscripts, selected reviewers, and recommended rejection or acceptance. He had been responsible not only for the whole field of prosthetic dentistry but also for functional aspects of the masticatory system and TMJ topics. He worked very efficiently and fast. This was based on his broad clinical experience and his profound knowledge of scientific dentistry. Without his support, this journal would not stay where it presently is. Wolfgang, it always was a great pleasure and an honor to work with you. Thanks a lot!

We now welcome Prof. Dr. Daniel Edelhoff as the new Associate Editor on board of this journal. He followed
Wolfgang Gernet as a chairman of the Department of Prosthetic Dentistry in Munich. Since many years, Daniel has served as a reviewer for us, and he thus has gained excellent insight into the management of this journal. I am very glad that Daniel has agreed to come on board. Daniel completed his undergraduate education as a dentist in 1991 at the School of Dentistry in Aachen. He gained his Dr. med. dent. degree in 1994 from the University of Aachen, Germany. From 1999 to 2001, he served as a Visiting Professor at the Dental Clinical Research Center of the Oregon Health and Sciences University, Portland, OR, USA, supported by a research grant from the German Society of Research (DFG). He completed his habilitation in 2003 in the area of all-ceramic restorative materials at the University of Aachen. In 2006, he moved to Munich, where he became professor and deputy head of the Department of Prosthetic Dentistry. Daniel had received a number of offers to become chairman in other universities (Charité Berlin and University Witten Herdecke), but he declined. Finally, last October, he took over the responsibilities from Prof. Gernet in Munich. We all wish Daniel good luck for his new position in Munich, and we are looking forward to a fruitful and effective cooperation for the good of this journal. Daniel-welcome!

Gottfried Schmalz

G. Schmalz $(\square)$

University of Regensburg, Regensburg, Germany

e-mail: gottfried.schmalz@klinik.uni-regensburg.de 